Coronavirus - SARS-CoV-1 - em 2002 e o Middle East Respiratory Syndrome Coronavirus - MERS-CoV - em 2012

\title{
Pandemia COVID-19 e Impacto no Desporto
}

Dr. Diogo Lino Moura ${ }^{1}, \mathrm{Dr}^{\mathrm{a}}$. Ana Dias ${ }^{2}$, Dr ${ }^{\mathrm{a}}$. Joana Pinheiro Torres ${ }^{3}$, Pedro Farinha ${ }^{4}$, Dr. Basil Ribeiro ${ }^{5}$, Prof. Dr. Carlos Robalo Cordeiro

${ }^{1}$ Docente da Faculdade de Medicina da Universidade de Coimbra (FMUC). Pós-graduação em Medicina Desportiva, Assistente Hospitalar de Ortopedia do Centro Hospitalar e Universitário de Coimbra (CHUC); ${ }^{2}$ Assistente Hospitalar de Pneumologia do Centro Hospitalar Lisboa Norte; ${ }^{3}$ Assistente de Medicina Geral e Familiar, Hospital Misericórdia da Mealhada, CHUC; ${ }^{4}$ Aluno de Medicina da FMUC; 5 Especialista de Medicina Desportiva. Al Nassr Football Club, Riade, KSA; ${ }^{6}$ Docente e Diretor da FMUC, Diretor do Serviço de Pneumologia do CHUC. Coimbra.

\section{RESUMO / ABSTRACT}

A epidemia de Coronavirus Disease 2019 disseminou-se globalmente em poucos meses, conduzindo a pandemia. Múltiplas medidas de saúde pública foram implementadas nos países afetados para conter e mitigar a disseminação da doença. A necessidade de distanciamento social leva a que esta pandemia tenha um impacto importante na sociedade e particularmente no desporto, provocando cancelamento e adiamento de treinos, competições e eventos. Neste artigo revemos as atualidades sobre a pandemia COVID-19, descrevemos brevemente o circuito dos atletas que forem suspeitos da infeção, resumimos o impacto da pandemia ao nível do desporto mundial, abordamos a saúde mental e terminamos com recomendações de exercício físico para durante a fase de isolamento.

Coronavirus Disease 2019 epidemy has disseminated worldwide in few months, turning into a pandemic. Multiple public health measures were implemented in affected countries in order to contain and mitigate disease dissemination. Social distance need makes this pandemic to have an impact at society and particularly in sports, causing cancellation and postponement of training sessions, competitions and sports events. In this paper we review the COVID-19 pandemic, briefly describe the circuit performed by athletes with infection suspicion, resume pandemic impact at sports worldwide, discuss the mental health and finally end with physical exercise recommendations during isolation time.

\section{PALAVRAS-CHAVE / KEYWORDS}

Coronavírus, COVID-19, epidemia, pandemia, desporto, distanciamento social, isolamento Coronavirus, COVID-19, epidemy, pandemic, sports, social distance, isolation

\section{Pandemia COVID-19}

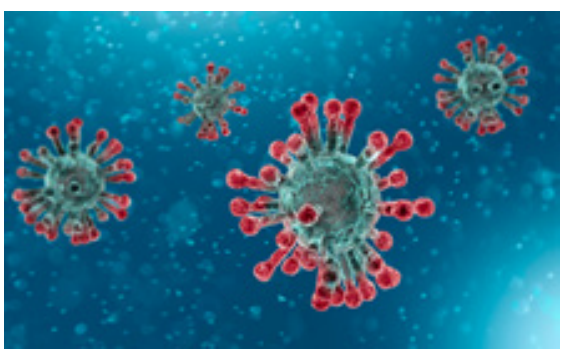

A epidemia de Coronavirus Disease 2019 (COVID-19) teve início em dezembro de 2019, quando uma série de casos de pneumonia de causa desconhecida surgiu na cidade de Wuhan, capital da província de Hubei, na China. No início do surto, a maioria dos doentes tinha ligação a um mercado de peixe, mariscos vivos e aves que acabou por ser encerrado. ${ }^{1} \mathrm{O}$ agente etiológico foi rapidamente identificado como um novo coronavírus, atualmente designado Severe Acute Respiratory Syndrome Coronavirus 2
(SARS-CoV-2) e que é capaz de transmissão pessoa a pessoa..$^{2,3} \mathrm{~A}$ síndrome respiratória aguda causada por este vírus foi denominada pela Organização Mundial de Saúde (OMS) como COVID-19. ${ }^{4}$ Disseminou-se globalmente em poucos meses e em Portugal os primeiros casos confirmados surgiram no início do mês de março. ${ }^{5}$ A 11 de março de 2020 a OMS classificou a COVID19 como pandemia, definida como uma epidemia com disseminação rápida a larga escala, neste caso com abrangência global. ${ }^{6}$ Os coronavírus circulam maioritariamente entre outros animais. No entanto, ao longo dos tempos, alguns vírus desta família adquiriram a capacidade de se transmitir e causar doença em humanos. Na maioria dos casos, os coronavírus humanos são responsáveis por quadros respiratórios ligeiros. Contrariamente, nas últimas duas décadas, dois coronavírus, o Severe Acute Respiratory Syndrome originaram epidemias de doença respiratória aguda grave, tal como o atual SARS-CoV-2.7

A transmissão do SARS-CoV-2 ocorre através de gotículas libertadas pela pessoa infetada quando esta tosse, espirra ou apenas fala e que atingem as mucosas da outra pessoa. O contacto com uma superfície infetada através das mãos, e seguidamente com os olhos, mucosa oral ou nasal, é também uma das formas de transmissão., ${ }^{1,8} \mathrm{~A}$ transmissão por via aérea pode ocorrer a nível hospitalar aquando da realização de procedimentos geradores de aerossóis e foi recentemente demonstrado que o SARS-CoV-2 permanece viável em aerossóis em suspensão até três horas. ${ }^{8,9}$ Os indivíduos sintomáticos são as principais fontes de contágio, mas está descrita a transmissão por assintomáticos. ${ }^{10,11}$

O período de incubação da doença pode durar até 14 dias, sendo que na maioria dos casos os sintomas surgem ao fim de 4-5 dias. ${ }^{3,12}$ Os principais sintomas da COVID-19 são febre, tosse e dispneia. A média da idade dos indivíduos infetados varia entre os 49 e 56 anos. ${ }^{7,13}$ Numa das séries de doentes admitidos num hospital de Wuhan, 49\% dos casos ocorreu em doentes com idades compreendidas entre 25-49 anos. ${ }^{7}$ De acordo com o que se observou em relação à população chinesa, cerca de $80 \%$ dos casos de COVID-19 correspondem a uma doença respiratória ligeira, sem ocorrência de pneumonia ou com pneumonia sem critérios de gravidade. Em 15\% dos casos observou-se um quadro mais grave, com pneumonia e insuficiência respiratória, enquanto 5\% evoluíram para falência respiratória, choque e/ou disfunção multiorgânica. ${ }^{14}$ Este último grupo de pacientes requer admissão em Cuidados Intensivos, sendo que $2.3 \%$ necessitam de ventilação mecânica invasiva. ${ }^{2}$ De acordo com o relatório do Center for Disease Control and Prevention chinês, que avaliou 72314 doentes com COVID-19, a mortalidade foi de $2.3 \%$, atingindo cerca de $15 \%$ nos idosos a partir dos 80 anos e $49 \%$ nos doentes críticos. ${ }^{14}$ No entanto, o espectro de gravidade 
da COVID-19 tem variado geograficamente, sendo que em Itália a proporção de doentes críticos e casos fatais tem sido superior. ${ }^{15} \mathrm{~A}$ idade avançada e a presença de comorbilidades, como doença cardiovascular, diabetes, doença respiratória crónica e neoplasia, são fatores de risco para maior gravidade e mortalidade. ${ }^{14,16}$

Aquando da declaração de pandemia de COVID-19 pela OMS registavam-se mais de 118000 casos em 114 países e o número de óbitos era de 4291. ${ }^{17}$ Estes números foram ultrapassados em larga escala nas semanas seguintes, reflexo da maior pandemia dos tempos modernos e fruto da elevada contagiosidade deste vírus. Entretanto, os Estados Unidos da América, a Itália e Espanha ultrapassaram a China em número de casos registados. ${ }^{18}$

Múltiplas medidas de saúde pública foram implementadas nos países afetados para conter e mitigar a disseminação da doença. O objetivo é atrasar a ocorrência do pico da pandemia, de forma a que os serviços de saúde tenham capacidade de resposta ao tratarem o menor número possível de doentes com COVID-19 ao mesmo tempo, evitando o colapso dos serviços. Ao nível da comunidade, as medidas divulgadas pretendem evitar a transmissão do vírus e incluem as medidas de etiqueta respiratória, a lavagem eficaz e frequente das mãos, bem como o uso de máscara. As medidas de distanciamento social têm vindo a ser gradualmente implementadas e incluem o isolamento dos casos de doença e a quarentena dos contactos, mas também a restrição de eventos de massas, o encerramento de escolas e de locais de trabalho. ${ }^{1,19}$

Para levar a cabo estas duras medidas de saúde pública, vários países decretaram o estado de emergência, cujas normas variam conforme o país. No nosso país o estado de emergência foi declarado a 18 de março de 2020, instituindo um dever geral de recolhimento domiciliário a todos os cidadãos. Neste contexto, a circulação na via pública ficou restrita ao essencial e apenas os estabelecimentos fornecedores de bens essenciais puderam manter atividade aberta e com regras de funcionamento, visando diminuir a transmissão do vírus. ${ }^{20}$
O impacto socioeconómico desta pandemia está ainda por determinar, mas seguramente após esta crise sanitária segue-se uma importante crise económica mundial para a qual os países se estão a tentar preparar. ${ }^{21}$ Enquanto na China o número de novos casos por dia já diminuiu significativamente, no ocidente, onde a COVID-19 chegou mais tarde, os números mantêm-se em crescendo, apesar do enorme esforço levado a cabo pelos governos e pela população, sendo o desfecho ainda pouco previsível. ${ }^{22}$

Dados observacionais têm demonstrado a utilidade de alguns fármacos nesta infecção. Estão atualmente em curso vários ensaios clínicos, no entanto não existe ainda nenhum fármaco aprovado para tratamento da COVID-19, aguardando-se também o desenvolvimento de uma vacina para prevenção da doença.

\section{Pandemia COVID-19 e o atingimento de atletas}

No início da epidemia, tal como recomendado para todas as empresas, cada grupo desportivo ou ginásio elaborou o seu plano de contingência. ${ }^{24}$ Uma vez em estado de emergência e com toda a atividade desportiva suspensa, perante as recomendações da Direção Geral de Saúde (DGS) nesta fase de mitigação, sempre que possível, o médico de Medicina Desportiva deverá aconselhar pelo telefone os atletas que a ele recorram com dúvidas ou sintomas de novo. De acordo com a Norma 004/2020 de 23/03/2020 da DGS, no decurso da fase de mitigação da pandemia de COVID-19, todos os indivíduos que desenvolvam um quadro respiratório agudo de tosse (persistente ou agravamento de tosse habitual), febre (temperatura $\geq 38^{\circ} \mathrm{C}$ ) ou dispneia são considerados suspeitos de COVID19. Na fase de mitigação da pandemia, na qual existe transmissão comunitária da doença, a história de contacto com um caso positivo ou a existência de ligação epidemiológica a zona de risco já não são critérios necessários para a suspeição. ${ }^{25}$

Na presença dos sintomas sugestivos, o atleta deverá ser aconselhado a utilizar as linhas telefónicas oficiais para integrar um circuito definido. Perante a ocorrência de sintomas, a Linha SNS24 deve ser contactada de acordo com a linha de comando da DGS. Em alternativa, o contacto poderá ser feito para linhas telefónicas criadas para este efeito sediadas em Unidades de Saúde Familiar ou Unidades de Cuidados de Saúde Personalizados locais ou regionais. ${ }^{25}$ Esta avaliação telefónica irá permitir o encaminhamento do paciente de acordo com a sua situação clínica e conforme se verifiquem condições adequadas de habitabilidade e exequibilidade do isolamento no domicílio.

Assim, se o quadro clínico for ligeiro e o paciente tiver condições para isolamento no domicílio, terá indicação para autocuidados, em isolamento no domicílio e sob vigilância. Se for necessária avaliação médica e for passível de se realizar ao nível dos cuidados de saúde primários, o doente é encaminhado para uma das Áreas Dedicadas COVID-19 nos Cuidados de Saúde Primários, nos quais os pacientes

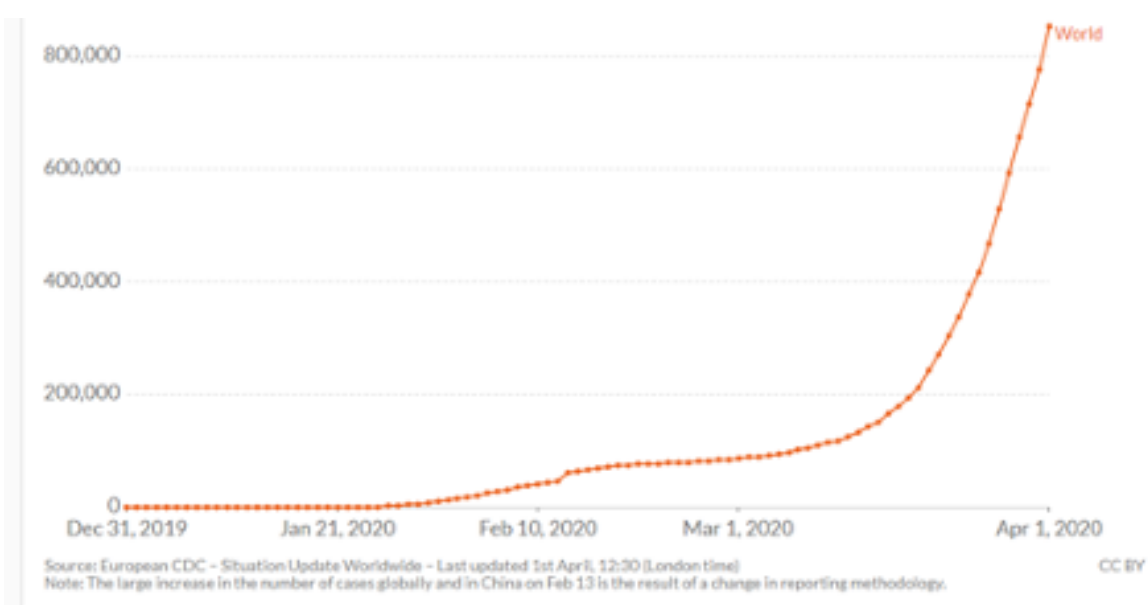

Figura 1 - Evolução do número total de casos COVID-19 confirmados no mundo. ${ }^{23}$ 


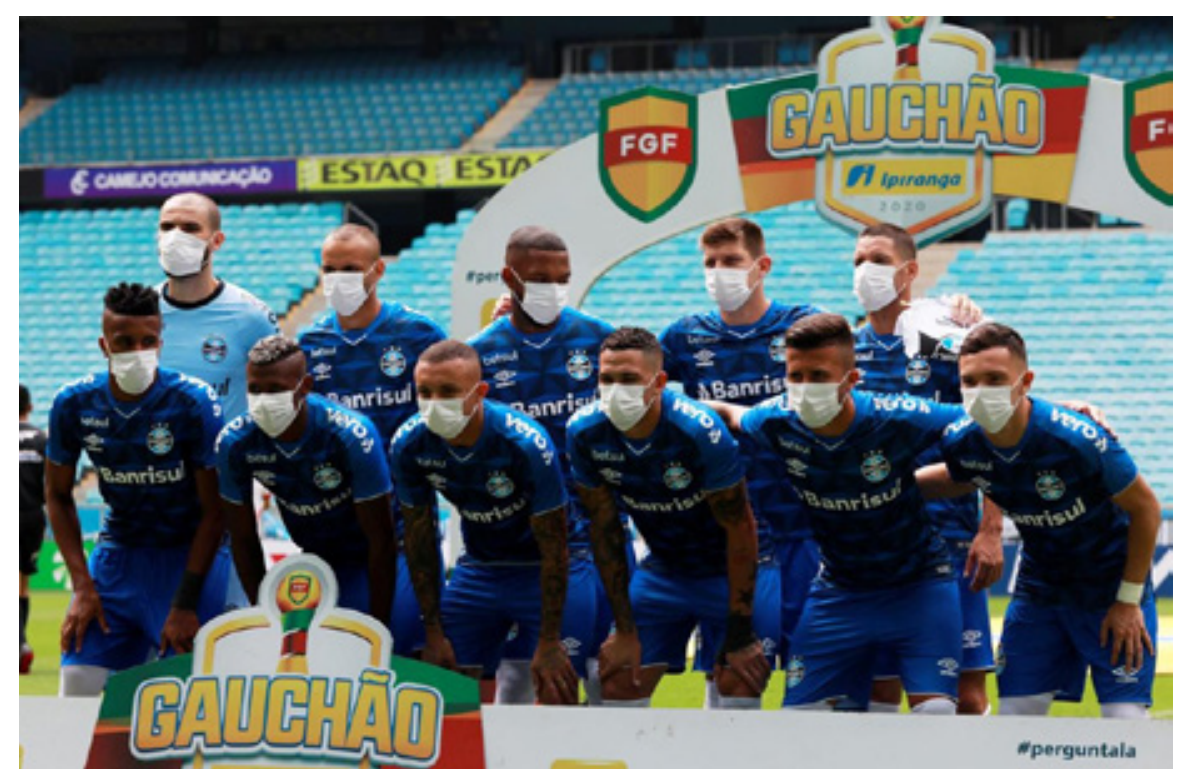

Figura 1 - https://www.thenational.ae/sport/other-sport/sporting-world-still-turning-despite-coronavirus-badminton-rugby-league-cricket-and-football-in-pictures-1.992939\#1

com suspeita ou infeção por SARS-CoV-2 têm circuitos separados dos restantes. ${ }^{25}$ Desta avaliação poderá resultar a necessidade de encaminhamento para uma das Áreas Dedicadas COVID-19 nos Serviços de Urgência (ADC-SU) do Serviço Nacional de Saúde (SNS) se se verificarem sinais clínicos de gravidade, tais como febre que não cede aos antipiréticos, dispneia para pequenos esforços, se o doente apresentar comorbilidades ou não se verificarem as condições habitacionais para o isolamento no domicílio, podendo ser necessária ativação do CODU/ INEM. ${ }^{25}$ Se à partida se verificar sintomatologia grave, o paciente poderá ser encaminhado diretamente para as ADC-SU pela linha telefónica que contactou. Salienta-se que, nesta fase, todos os doentes com suspeita de COVID-19 devem ser submetidos a teste laboratorial para SARS-CoV-2, seja em regime de ambulatório ou em internamento hospitalar. ${ }^{25}$ Uma vez que a linha SNS24 se encontra altamente sobrecarregada, vários médicos têm-se disponibilizado para

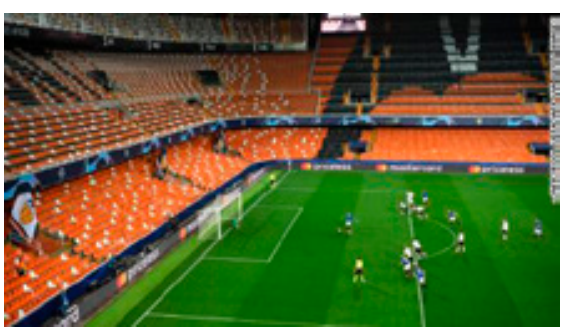

Figura 2 - As medidas de suspensão ou cancelamentos de eventos desportivos esclarecer dúvidas de saúde e renovar medicação habitual de adeptos e associados, contribuindo desta forma para aliviar o SNS durante a pandemia.

\section{Pandemia COVID-19 e impacto no desporto}

A pandemia da COVID-19 tem tido também ao nível do mundo do desporto um impacto negativo altamente significativo, tanto a nível desportivo propriamente dito, como económico à escala mundial, como já não se observava desde a $2^{a}$ Guerra Mundial. Em todo o Mundo, as competições desportivas têm sido suspensas ou canceladas, incluindo os maiores eventos desportivos agendados para 2020, tais como os Jogos Olímpicos e Paralímpicos de Tóquio 2020 ou o Euro 2020, ambos atualmente com reagendamento previsto para 2021. ${ }^{26,27} \mathrm{Tal}$ como referido previamente, estas medidas têm carácter preventivo, procurando com a minimização do contacto entre atletas, equipas técnicas, adeptos e respeitando a quarentena, minimizar a disseminação da COVID-19 no âmbito desportivo, quer nos treinos, quer nas competições.

O impacto internacional poderá ter repercussões devastadoras na indústria desportiva como a conhecemos, na medida em que as modalidades não têm alternativa senão a suspensão das suas competições.
Referimo-nos, por exemplo, à suspensão dos desportos que geram as maiores receitas financeiras nos Estados Unidos da América, como a Major League Soccer (MSL), a National Basketball Association (NBA) e a National Hockey League (NHL), o que tem graves e evidentes consequências vários níveis. ${ }^{28}$

Apresentamos em seguida algumas das medidas de suspensão ou cancelamentos de competições em diversas modalidades desportivas decorrentes da pandemia. No futebol a nível internacional, a UEFA anunciou o adiamento do Euro 2020, onde iria participar a Seleção Nacional Portuguesa, apresentando atualmente novas datas previstas de 11 de Junho a 11 de Julho de 2021. Na mesma linha, a Liga das Nações 2021, o Campeonato Europeu de Futebol Sub-21 e o Campeonato Europeu Feminino 2021 foram igualmente adiados. A Copa América 2020 foi também adiada para 2021, igualmente com o intuito de permitir que os atletas sul-americanos que jogam em clubes europeus possam concluir os respetivos campeonatos, caso estes sejam retomados. Outros exemplos são Inglaterra, Escócia e Irlanda do Norte, Alemanha, Itália e Espanha, em que toda a atividade no futebol foi suspensa, pelo menos até ao início de junho, tratando-se, no entanto, de uma realidade extensível a praticamente todo o Mundo. ${ }^{26}$ Ao nível do atletismo, o Campeonato Mundial de Atletismo em Pista Coberta foi adiado. As maratonas, provas desportivas com milhares de participantes à escala mundial, foram igualmente afetadas. A Maratona de Londres, agendada para 26 de Abril de 2020, foi adiada para dia 4 de Outubro do mesmo ano, sendo que as Maratonas de Boston, Amesterdão, Paris e Barcelona foram igualmente adiadas. ${ }^{28}$ No ciclismo, a Union Cycliste Internationale anunciou a suspensão de todas as atividades. Diversas provas deste desporto foram adiadas, entre as quais o Giro d'Italia, que seria o primeiro Grand Tour da época. Na natação, a British Swimming confirmou que a Diving World Series foi adiada. Na mesma via, os campeonatos britânicos de natação, agendados para abril, foram cancelados. Ao nível do judo, a Federação Internacional de Judo 
cancelou os eventos de qualificação para os Jogos Olímpicos até dia 30 de Abril. ${ }^{26}$ No boxe, os torneios de qualificação Europeus, Americanos e Mundiais para os Jogos Olímpicos foram suspensos, medida decretada pelo Comité Olímpico Internacional. No ténis, escalão masculino e feminino, as provas foram suspensas internacionalmente até 7 de junho, sendo que os rankings ATP (Associação dos Tenistas Profissionais) e WTA (Women's Tennis Association) estão suspensos. ${ }^{28}$ No râguebi, a competição das Seis Nações foi adiada. No beisebol, a Major League Baseball anunciou que a época desportiva de 2020 irá começar com adiamento de pelo menos 8 semanas. ${ }^{26}$ Quanto à Fórmula 1, o Gran Prix do Azerbeijão foi recentemente adiado, determinando-se que não ocorrerão corridas de Fórmula 1, no melhor dos cenários, até meio de Junho. ${ }^{28}$

Em Portugal, à semelhança da realidade mundial, a atual pandemia deixou o desporto de quarentena. As diferentes federações têm anunciado a suspensão das respetivas competições, sendo que as principais modalidades coletivas estão interrompidas. No andebol, a fase regular do campeonato nacional tinha acabado de terminar quando foi decretada a suspensão da competição. O basquetebol, o futsal, o hóquei patins e o voleibol são modalidades cuja prática foi interrompida, sendo que a Federação Portuguesa de Voleibol determinou 31 de agosto de 2020 como provável data para a retoma das atividades. ${ }^{29}$ No que respeita ao futebol, as competições profissionais foram suspensas e as competições de formação todas canceladas. Em comunicados, a Federação Portuguesa de Futebol declarou que se dão por concluídas as competições nacionais de todos os escalões de formação de futebol e futsal, masculinas e femininas, não resultando destas qualquer efeito desportivo imediato, determinando assim que não serão atribuídos títulos, nem aplicado o regime de subidas e descidas. ${ }^{30}$ Mais recentemente foram também dadas por concluídas, sem vencedores, títulos e subidas ou descidas, todas as competições nacionais não profissionais seniores de futebol, incluindo o Campeonato de Portugal ( $3^{a}$ divisão nacional). ${ }^{31}$ Tal como referido do ponto de vista da sociedade em geral, também os atletas e os clubes desportivos estão a sofrer o impacto financeiro da interrupção da atividade desportiva, o que em alguns casos poderá colocar em causa a viabilidade económica de algumas instituições. A ausência de jogos diminui consideravelmente as receitas dos clubes em várias áreas (bilheteiras, televisão, patrocínios, atividades de formação, entre outros), o que pode colocar em causa o pagamento dos vencimentos dos seus funcionários, entre os quais os atletas. Vários clubes já renegoriaram alguns contratos de atletas em termos de redução salarial, de modo a poder ajustá-los à nova realidade económica. De maneira semelhante também a sustentabilidade financeira de federações e associações desportivas poderá estar seriamente em causa. Esta situação de crise económica poderá na época pós-pandemia comprometer a continuidade da atividade desportiva de formação de vários jovens como também das competições como as conhecemos até hoje.

\section{Isolamento social e impacto no desporto}

O adiamento e cancelamento das provas é apenas parte da preocupação das federações, clubes e atletas. A gravidade da pandemia obrigou ao isolamento social, o que identifica uma mudança radical na vida do atleta, especificamente na rotina diária. No sentido de minimizar o efeito do isolamento na componente física do atleta, frequentemente os atletas seguem planos de treino domiciliário sob a orientação dos treinadores e clubes que, embora permitam manter um determinado nível de treino em volume e intensidade adequados, falham na capacidade de mimetizar os momentos e as necessidades físicas do jogo. Este fenómeno implicará necessidade acrescida de monitorização individual do atleta no regresso à competição, no sentido de minimizar a ocorrência de lesões na retoma dos níveis de exigência competitiva prévia. Para além da dimensão física, surge a questão da saúde mental do atleta. ${ }^{32} \mathrm{~A}$ permanência em casa é desagradável, pois não só não se sabe qual será a duração, como existe privação da liberdade, do contacto direto com os amigos e familiares. Como tal, face a esta nova realidade é natural ter medo e estar apreensivo sobre o presente e o futuro, é natural a desilusão perante tantas dúvidas sem resposta e é natural questionar os outros e os próprios. O isolamento social comporta igualmente preocupações relativas ao receio de ser infetado, de estar a colocar em risco as carreiras desportivas, da perda de rendimento e de problemas económicos.

Recomenda-se que nesta fase o atleta entenda que o melhor modo de ultrapassar esta situação é aceitá-la e tomar consciência que não mudará nas próximas semanas ou meses. É determinante perceber que há profissionais de várias áreas a trabalhar arduamente em benefício de todos os outros, com maior ou menor risco, com o objetivo de resolver do melhor modo este problema. Só estas noções já darão alguma saúde mental. Deve-se evitar desenvolver sentimentos de tristeza, raiva, culpa, frustração, ansiedade, que poderão ser crescentes com o evoluir do tempo. É natural estes sentimentos evoluirem com o decorrer da quarentena e ao mesmo tempo é obrigação do ser humano contrariar esta tendência. A frustração de não poder realizar tarefas da vida diária, profissionais ou outras, aumenta com o tempo, no entanto o passar do tempo é também sinónimo de que a solução está mais perto. O pessimista seguirá com mais facilidade o caminho negativo, enquanto o otimista verá uma oportunidade para outras atividades, para outras relações e para se inventar ou se descobrir. 0 produto humano inacabado tem agora esta oportunidade que lhe foi concedida e tem obrigação de tirar dela o melhor proveiro. Deve procurar ganhar o tempo reinventando-se em vez de desperdiçar este período, vendo-o como perda de tempo.

Recomendam-se várias estratégias para melhor enfrentar a prolongada permanência no domicílio nesta fase difícil na vida de todos, entre as quais:

- Comunicar com alguém em que se confia, falar com com quem se gosta e mesmo falar com a pessoa 
com que habitualmente não se fala são boas opções. Comunicar é fundamental, enviar mensagens pelas vias digitais e, melhor, telefonar a alguém é saudável, é importante ser ouvido e falar, especialmente nos momentos menos bons;

- Ver filmes, programas sobre viagens e mundo animal, programas humoristas:

- Iniciar um hobby é também interessante; arranjar algo em casa, organizar as fotografias do telemóvel, organizar concursos e jogos de vídeos caseiros, experimentar ler um livro são atividades que mantêm a mente ocupada e saudável;

- Manter um estilo de vida saudável: dieta equilibrada (refeições pequenas e frequentes, de fácil digestão, pobre em gorduras, rica em fruta e legumes), períodos saudáveis de sono (tentar manter os mesmos horários), hidratação (privilegiando a água); evitar fumar, ingerir álcool ou usar drogas sociais para controlar as emoções;

- Praticar atividade física, mesmo que pouca, é necessária e serão as circunstâncias individuais que ditarão o modo de a executar. Os atletas terão certamente os planos de treino dos seus treinadores, mas a restante população deverá olhar à sua volta e descobrir o modo para se manter ativa, em sessão única ou repartida ao longo do dia. É expectável que o isolamento social aumente o sedentarismo, permanecendo mais tempo sentado ou deitado, reduzindo os índices de atividade física, com consequente menor consumo energético. ${ }^{33}$ Estes fenómenos poderão também ser responsáveis pelo agravamento do quadro clínico de pacientes com patologias crónicas. ${ }^{33,34}$ No intuito de limitar hábitos de comportamento sedentário deve-se evitar, sempre que possível, permanecer mais de 30 minutos consecutivos na posição de sentado, reclinado ou deitado (se acordado), devendo levantar-se e caminhar pela casa, por exemplo enquanto fala ao telemóvel ou durante intervalos publicitários. ${ }^{35}$ Neste sentido, o exercício físico é seguro e deverá ser praticado durante a pandemia, requerendo no entanto algumas medidas preventivas no intuito de minimizar o risco de infeção Covid-19.33,35 Para indivíduos que pratiquem exercício físico de recreação, dada a possibilidade de existência de indivíduos infetados assintomáticos e possível transmissão entre pares, é recomendável a prática desportiva individual. ${ }^{35} \mathrm{O}$ recomendado é praticar exercício físico no domicílio. Recomendam-se exercícios aeróbios, de equilíbrio, de fortalecimento e de alongamento muscular ou a combinação dos mesmos. ${ }^{33}$ Exemplos de exercícios em casa são o simples caminhar pelas divisões da casa com o intuito de interromper períodos prolongados de posições sentado e deitado, realizar atividades domésticas, tratar do jardim ou da horta ou até mesmo dançar. Outros exemplos são elevar pesos moderados (sacos de compras ou garrafas), realizar lunges, agachamentos, levantar e sentar da cadeira e flexões de braços. ${ }^{33,36}$ As plataformas online com programas de exercícios são também uma estratégia recomendável para instruir, orientar e motivar o exercício em casa através de programas de exercícios gerais ou individualizados, desde que adequada à condição física de cada indivíduo. ${ }^{33,36} \mathrm{~A}$ pesquisa no Google, introduzindo "exercício físico em casa e coronavirus" devolve centenas de endereços eletrónicosonde esclarecem e exemplificam uma miríade enorme de exercícios Se o exercício for praticado fora de casa, nomeadamente nas áreas adjacentes à residência, deverão aplicar-se medidas de precaução gerais, entre as quais evitar tocar com as mãos na cara ou pescoço durante e após o exercício e lavagem das mãos após o exercício durante um período mínimo de 20 segundos. ${ }^{35}$ Para indivíduos previamente sedentários e com comorbilidades que habitualmente não praticam exercício físico será pertinente uma avaliação médica prévia e eventual prescrição do tipo, frequência, intensidade e volume de treino adequado às suas particularidades. ${ }^{35,37} \mathrm{O}$ exercício físico não está recomendado em indivíduos que desenvolvam os sintomas prováveis da infeção Covid-19, nomeadamente febre, tosse, dispneia e astenia, devendo nestes casos seguir os passos recomendados previamente pela DGS. ${ }^{36}$ A procura da informação científica válida e fidedigna é necessária, devendo-se reduzir ao essencial a audição e leitura de notícias relativamente à pandemia, mantendo sempre espírito crítico. Nesta fase da pandemia são sobretudo mais difundidas as notícias negativas, o que causa desconforto. As pessoas têm a expetativa e procuram notícias positivas, que para já são escassas, mas é importante entender que estas surgirão mais tarde ou mais cedo. Atenção às notícias e comentários de indivíduos que não são da área científica, baseados apenas em opiniões pessoais por vezes pouco corretas e muitas vezes pessimistas, tornando o cenário pior do que na realidade é. É também papel importante dos médicos e profissionais de saúde em geral combater a desinformação e o alarmismo relativamente a esta temática tão presente diariamente nesta fase das nossas vidas.

\section{Conclusão}

A pandemia COVID-19 tem sido um dos maiores desafios com que o mundo moderno se deparou e espera-se que tenha consequências importantes e duradouras a vários níveis da sociedade. O desporto é apenas um dos domínios da sociedade altamente afetados pela pandemia e cabe a todas as pessoas de alguma maneira envolvidas nesta área trazer de volta o desporto como o conhecemos, restaurando progressivamente a vitalidade de todas as modalidades e seus principais eventos. Para isso, a Medicina Desportiva está na linha da frente e terá um papel fundamental ao longo de todo o difícil e duradouro período de convalescença pós-pandemia, em que todos teremos de nos confrontar e ultrapassar dificuldades a vários níveis da sociedade e em particular no Desporto.

\section{Correspondência}

Dr. Diogo Lino Moura

Faculdade de Medicina da Universidade de Coimbra

dflmoura@gmail.com 


\section{Bibliografia}

1. Direção Geral da Saúde. Plano Nacional de Preparação e Resposta à Doença por Novo Coronavírus (COVID-19). 2020 - https://www. dgs.pt/documentos-e-publicacoes/plano-nacional-de-preparacao-e-resposta-para-a-doenca-por-novo-coronavirus-covid-19. aspx - Acesso a 2-04-2020

2. Guan WJ, Ni ZY, Hu Y, Liang WH, et al. Clinical Characteristics of Coronavirus Disease 2019 in China. N Engl J Med. 2020 Feb 28.

3. Li Q, Guan X, Wu P, Wang X et al. Early Transmission Dynamics in Wuhan, China, of Novel Coronavirus-Infected Pneumonia. N Engl J Med. 2020; 382(13):1199-1207.

4. World Health Organization. Coronavirus disease (COVID-19) outbreak - http://www. euro.who.int/en/health-topics/health-emergencies/coronavirus-covid-19/ novel-coronavirus-2019-ncov - Acesso a 2-04-2020

5. Direção Geral da Saúde. Casos de infeção por novo Coronavírus (COVID-19. Comunicado C160_75_v1 de 02/03/2020. - https:// covid19.min-saude.pt/wp-content/ uploads/2020/03/ Atualiza\%C3\%A7\%C3\%A3o-de-02032020-1728.pdf - Acesso a 2-04-2020

6. https://www.who.int/dg/speeches/detail/ who-director-general-s-opening-remarks-at-the-media-briefing-on-covid-19-6-april-2020. - Acesso a 8-04-2020

7. Huang C, Wang Y, Li X, et al. Clinical features of patients infected with 2019 novel coronavirus in Wuhan, China. Lancet. 2020; 395:497.

8. van Doremalen N, Bushmaker T, Morris DH, et al. Aerosol and Surface Stability of SARS-CoV-2 as Compared with SARS-CoV-1. N Engl J Med. 2020.

9. https://www.who.int/publications-detail/ report-of-the-who-china-joint-mission-on-coronavirus-disease-2019-(covid-19) - Acesso a 2-04-2020

10. Rothe C, Schunk M, Sothmann P, et al. Transmission of 2019-nCoV Infection from an Asymptomatic Contact in Germany. N Engl J Med. 2020; 382(10):970-971.

11. Bai Y, Yao L, Wei T, et al. Presumed Asymptomatic Carrier Transmission of COVID-19. JAMA. 2020 Feb 21. DOI: 10.1001/ jama.2020.2565.

12. Lauer SA, Grantz KH, Bi Q, et al. The Incubation Period of Coronavirus Disease 2019 (COVID-19) From Publicly Reported Confir- med Cases: Estimation and Application. Ann Intern Med. 2020 Mar 10.

13. Wang, D, Hu B. et al. Clinical characteristics of 138 hospitalized patients with 2019 novel coronavirus-infected pneumonia in Wuhan, China. JAMA. 2020 Feb 7.

14. Wu Zunyou, McGoogan Jennifer M. Characteristics of and Important Lessons from the Coronavirus Disease 2019 (COVID-19) Outbreak in China. Summary of a Report of 72 314 Cases from the Chinese Center for Disease Control and Prevention. JAMA. 2020 February 24.

15. Onder G, Rezza G, Brusaferro S. Case-Fatality Rate and Characteristics of Patients Dying in Relation to COVID-19 in Italy. JAMA. 2020 March 23.

16. Zhou Fei, Yu Ting, Du Ronghui, et al. Clinical course and risk factors for mortality of adult inpatients with COVID-19 in Wuhan, China: a retrospective cohort study. The Lancet. 2020 March 28; 395(10229): P1054-1062.

17. www.who.int/dg/speeches/detail/who-director-general-s-opening-remarks-at-the-media-briefing-on-covid-19. 11-march-2020. - Acesso a 2-04-2020

18. https://www.euronews.com/2020/03/25/ coronavirus-spain-surpasses-china-in-the-overall-number-of-covid-19-deaths. - Acesso a 2-04-2020

19. World Health Organization. Responding to community spread of COVID-19. Interim guidance. 7 March 2020. WHO/ COVID-19/Community transmission/ v1. https://apps.who.int/iris/bitstream/ handle/10665/331421/WHO-COVID-19-Community_Transmission-2020.1-eng. pdf? sequence $=1 \&$ amp;isAllowed $=\mathrm{y}-$ Acesso a 2-04-2020

20. Decreto Lei n²-A 2020. Diário da República n. ${ }^{\circ}$ 57/2020, $1^{\circ}$ Suplemento, Série I de 2020-03-20. https://dre.pt/application/conteudo/130473161 - Acesso a 2-04-2020

21. https://ec.europa.eu/info/live-work-travel-eu/health/coronavirus-response_en. Acesso a 2-04-2020

22. https://www.worldometers.info/coronavirus/. - Acesso a 2-04-2020

23. https://ourworldindata.org/ coronavirus\#understanding-exponential-growth. - Acesso a 2-04-2020

24. Direção Geral da Saúde. Infeção por SARS-CoV-2 (COVID-19) Procedimentos de prevenção, controlo e vigilância em empresas. Orientação 006/2020 de 26/02/2020. Direção Geral da Saúde. - https://www.dgs.pt/directrizes -da-dgs/orientacoes-e-circulares-informativas/orientacao-n-0062020-de-26022020 -pdf.aspx - Acesso a 2-04-2020

25. Direção Geral da Saúde. COVID-19: Fase de Mitigação - Abordagem do Doente com Suspeita ou Infeção por SARS-CoV-2. Norma 004/2020 de 23/03/2020. Direção Geral da Saúde. - https://www.dgs.pt/directrizes-da-dgs/normas-e-circulares-normativas/ norma-n-0042020-de-23032020-pdf.aspx Acesso a 2-04-2020

26. https://www.independent.co.uk/sport/ sport-football-basketball-rugby-olympics-cancelled-coronavirus-impact-around-the-world-a9398186.html. - Acesso a 4-04-2020

27. https://www.bbc.com/sport/football/51909518. - Acesso a 4-04-2020

28. https://www.aljazeera.com/news/2020/03/ coronavirus-sporting-events-affected-outbreak-200310084205890.html. - Acesso a 4-04-2020

29. https://desporto.sapo.pt/modalidades/ artigos/covid-19-deixou-desporto-de-quarentena-como-estavam-os-campeonatos-nacionais-das-varias-modalidades. - Acesso a 4-04-2020

30. https://www.fpf.pt/News/Todas-as-not\%C3\%ADcias/Not\%C3\%ADcia/ news/26603. - Acesso a 4-04-2020

31. https://www.fpf.pt/News/Todas-as-not\%C3\%ADcias/Not\%C3\%ADcia/ news/26667 - Acesso a 8-04-2020

32. https://www.bbc.com/news/uk-scotland-edinburgh-east-fife-51974974. - Acesso a 8-04-2020

33. Chen P, Mao L, Nassis GP, Harmer P, Ainsworth BE, Li F. Coronavirus disease (COVID-19): The need to maintain regular physical activity while taking precautions. J Sport Health Sci. 2020; 9:103-4.

34. Owen N, Sparling PB, Healy GN, Dunstan DW, Matthews CE. Sedentary behavior: emerging evidence for a new health risk. Mayo Clin Proc. 2010; 85:1138-41.

35. Zhu W. Should, and how can, exercise be done during a coronavirus outbreak? An interview with Dr. Jeffrey A. Woods. J Sport Health Sci. 2020; 9:105-7.

36. https://www.dgs.pt/programa-nacional-para-a-promocao-da-atvidade-fisica/ ficheiros-externos-pnpaf/news_afisolamentosocial-pdf.aspx. - Acesso a 8-04-2020

37. http://www.femede.es/documentos/Recomendaciones_enfermedad_cronica-01.pdf. - Acesso a 8-04-2020 


\section{O coronavírus: a opinião do cardiologista e do infecciologista}

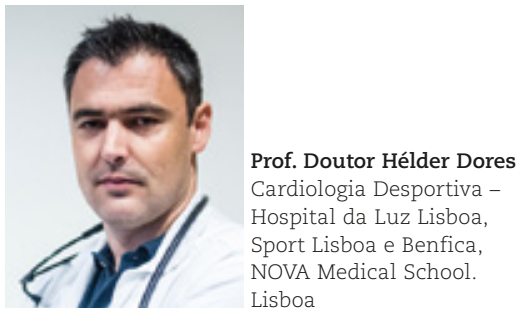

1. No atleta infetado assintomático o coração pode ser afetado?

Sim, podem existir lesões cardíacas subclínicas, como a lesão miocárdica aguda ou miocardite.

\section{A exemplo de outras infeções} virais, é expectável a ocorrência de miocardites?

Está comprovada a associação entre COVID-19 e complicações cardíacas, nomeadamente a miocardite aguda. Alguns estudos descrevem elevação da troponina em 10-30\% dos doentes, constituindo um marcador de risco/prognóstico.

\section{Faz sentido fazer o teste do coronavírus a todos os atletas (profissionais e não profissionais) e staff?}

Este ponto é atual pela pretensão em reiniciar as competições. Quantos mais testes forem realizados melhor. Contudo, além de realizar estes ou testes de imunidade, deve ser definida a orientação subsequente, caso seja positivo ou negativo. A heterogeneidade de atletas/ clubes implica também garantir um acesso universal e capacidade económica para a sua realização.

4. As orientações que vêm de Itália sugerem a realização de "testes de ergometria, ecocardiograma, espirometria e análises" nos atletas assintomáticos...

Este documento direciona-se sobretudo ao futebol profissional e apresenta inconsistências quanto à metodologia e aplicabilidade prática. Concordo que mesmos os atletas infetados assintomáticos devam ser avaliados. Esta avaliação deve incluir um exame objetivo detalhado e clarificação do contexto epidemiológico, podendo incluir alguns dos exames referidos.

\section{Dentro do bom senso e do exequível para o universo dos atletas, o que é aconselhável fazer em termos cardiológicos?}

Perante uma doença com aspetos desconhecidos, sobretudo as sequelas a longo prazo, é necessário bom senso, correndo o risco de se pecar por excesso. A nível cardiológico, além da avaliação clínica é importante investigar a presença de sintomas e ter em conta as características do atleta e do desporto. Se foi avaliado em unidades de saúde devem ser analisados os exames prévios e esclarecida a evolução da doença. Quanto aos exames de primeira linha, sobretudo na presença de sintomas, como uma das principais implicações é a lesão miocárdica aguda/miocardite, justifica-se ecocardiograma transtorácico, prova de esforço máxima e, se apropriado, Holter 24 horas. Se houve elevação da troponina, caso não tenha sido já efetuada, deve realizar-se ressonância magnética. O diagnóstico de miocardite levará à desqualificação 3-6 meses.

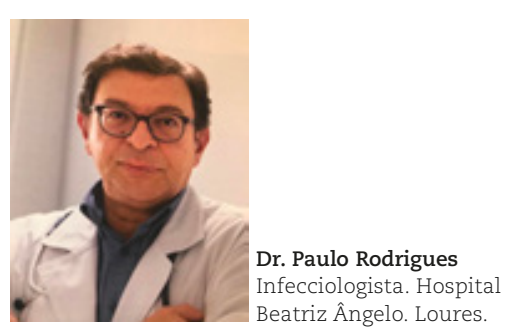

1. O coronavírus é um problema para o jovem atleta?

Sim. A COVID-19 constitui neste momento uma pandemia. Tem um leque vasto de gravidades, que vão desde casos assintomáticos até fatais. Embora a maioria dos casos graves e das mortes ocorram em pessoas de idade mais avançada ou com comorbilidades, está descrita doença muito grave, e até mortal, em pessoas jovens e previamente saudáveis. Acresce o confinamento social, também com grande impacto nos atletas e na realização de eventos.

2. $O$ atleta infetado, mas assintomático, pode praticar desporto normalmente?

Não. Qualquer pessoa infetada constitui uma fonte de transmissão importante. Acresce que no decorrer de uma infeção é muito importante o repouso e a evicção de esforços físicos intensos, que podem resultar em agravamento clínico. O atleta só deverá praticar desporto normalmente depois de observação médica e exames.

\section{E o risco de contágio no treino ou no jogo de futebol?}

Existe risco de contágio, quer no treino, quer no jogo. Os desportos coletivos, sobretudo aqueles com contacto físico direto, são aqueles em que é mais fácil a transmissão da doença.

\section{Fala-se muito em anti-inflama- tórios. Podem continuar a tomar na lesão?}

Houve relatos médicos de agravamento clínico com o uso de ibuprofeno, até à data não completamente confirmado. Por esse motivo, em contexto de infeção por SARS-Cov-2 devem, provavelmente, devem ser evitados.

\section{O desporto em geral só estará seguro com a vacina? Para quando se prevê?}

Sim. Tanto o desporto como a vida em geral, só poderão ser retomados com toda a segurança depois do aparecimento dum tratamento altamente eficaz ou, idealmente, de uma vacina que, na melhor das hipóteses, não estará disponível para uso generalizado em menos de 12 a 18 meses. 


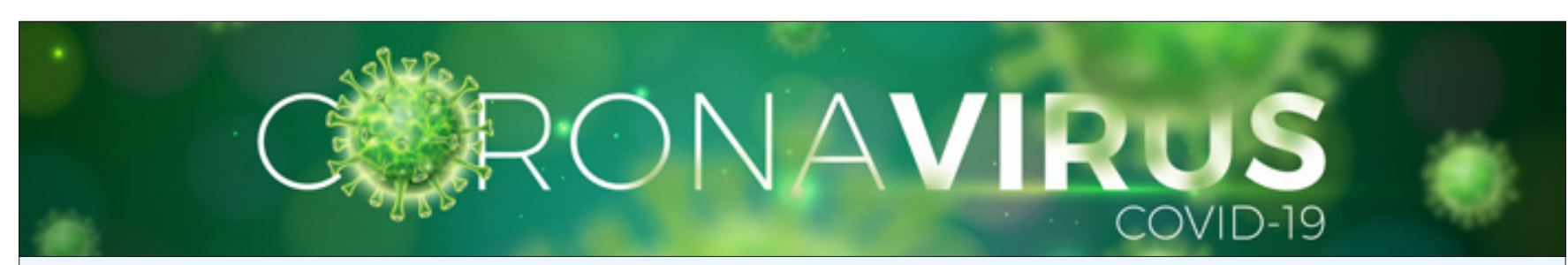

\section{Cronologia COVID-19*}

\section{Dezembro, 2019}

12. As autoridades de saúde chinesas iniciam uma investigação sobre uma pneumonia viral. Os doentes tinham em comum uma visita ao mercado local. - O médico, de 34 anos de idade, divulga a notícia e diz aos seus colegas que havia uma nova doença por coronavírus. Havia 7 pacientes naquele momento.

31 . A polícia inicia investigação sobre 8 pessoas por difamação sobre um novo surto de doença infeciosa. A Organização Mundial da Saúde (OMS) é informada.

\section{Janeiro, 2020}

7 . Os chineses informam que há um novo coronavírus

30 - OMS: declara o coronavírus uma emergência internacional. China: 7711 casos e 170 mortes.

31 - Primeiros casos na Índia, Filipinas, Rússia, Espanha, Suécia, Reino Unido, Austrália, Canadá, Japão, EUA e Emirados Árabes Unidos.

\section{Fevereiro, 2020}

2 - Primeira morte fora da China: Filipinas; dias depois 1 morte em Hong Kong.

6 - O médico que primeiro anunciou a doença morre.

11 - Três semanas após a introdução das medidas restritivas, o número de casos na China começou a diminuir. OMS atribui o nome de COVID-19 à doença.

12 - Há 175 pessoas no cruzeiro no navio Diamond Princess que estão infetadas e nos dias seguintes mais 700 pessoas foram infetadas.

19 - Irão: relata 2 mortes. Em Milão joga-se o Atalanta - Valencia para a Liga dos Campeões. Existem 44.000 fãs. Alguns especialistas consideraram esse momento como uma "bomba biológica".

20 - Primeiro paciente na região da Lombarda Itália; mais 36 durante nas 24 horas.

24 - Primeiros casos no Bahrein, Iraque, Kuwait, Afeganistão e Omã.

25 - Uma equipe de especialistas conclui que a epidemia chinesa atingiu o pico.

\section{Março, 2020}

2 - Primeiros dois casos (um é médico) de COVID em Portugal

7 - Informações oficiais relatam diminuição de cerca de $17,5 \%$ nas exportações chinesas.

8 · 16 milhões de pessoas na Lombardia, Itália, estão em quarentena.

9 - Irão: liberta 70.000 prisioneiros por causa do surto.

10 . O presidente da China, Sr. Xi Jinping, visita a cidade de Wuhan e declara uma vitória provisória nesta batalha contra o coronavírus. 16 hospitais temporários estão fechados.
11 - OMS: declara o surto como uma pandemia

12 - Itália: fecha todas as lojas, exceto farmácias e supermercados.

- França: todas as escolas e universidades estão fechadas.

13 - Declaração de situaçãode alerta em todo o território nacional

- O primeiro ministro do Reino Unido cria a noção de imunidade de rebanho.

- Os jogos da Liga dos Campeões e da Liga Europa são cancelados.

- O governo espanhol "fecha" todo o país e pede que as pessoas fiquem em casa;

- França: todos os locais públicos não essenciais são fechados após a meia-noite.

16 - Primeira morte em Portugal: masculino, 80 anos, ex-massagista do futebol.

17 . 7 milhões de pessoas que vivem na área da baía de São Francisco (EUA) são aconselhadas a abrigarem-se e são proibidas de sair para casa.

18 - Foi decretado o estado de emergência em Portugal e renovado a 3/04 até 17/4.

19 - Pela primeira vez, não há novos casos em Wuhan e Hubei.

- O governador da Califórnia ordena que 40 milhões de pessoas fiquem em casa.

20 - Itália: em 24 horas 6.000 novos casos e 627 mortes. - Espanha: o crime diminui 50\%; China

- Sem novos casos após 3 dias.

- Nova York: torna-se o local de maior gravidade a nível mundial da doença; é declarada quarentena geral.

23 . O Reino Unido implementa medidas de contenção.

24 - Espanha: 12\% dos pacientes são trabalhadores da saúde.

· Índia: 3 mil milhões de pessoas estão em quarentena. - Os Jogos Olímpicos são cancelados.

25 - EUA: são agora o país com mais casos no Mundo.

27 . O Primeiro Ministro e o Ministro da Saúde do Reino Unido têm testes positivos.

29 - Itália: 50 médicos morreram por causa do coronavírus.

\section{Abril, 2020}

4. Mais de 10000 pessoas infetadas em Portugal.

6 - O primeiro-ministro do Reino Unido é internado nos cuidados intensivos.

- Portugal ultrapassa os 300 mortos pelo COVID-19.

8 - O vírus está em 209 países e territórios

15 . Há mais de 2 milhões de infetados em todo o Mundo.

16 - A SPMD organiza um webinar sobre o COVD-19 e o Desporto.

26 - Há 3303717 casos reportados em todo o Mundo e 25045 em Portugal.

*Kamps, B S, Hoffman, C. COVID Reference. $1^{\text {a }}$ ed, 2 de abril 2020. www.CovidReference.com 


\section{○ $O$ regresso do futebol ?}

Dr. Basil Ribeiro

Medicina desportiva, Riade, KSA

Todos conhecemos a situação atual e todos temos vivido o passado. Falta aqui o futuro para onde vamos em busca da retoma da vida normal, pelo menos semelhante à que tínhamos. Contudo, ninguém tem respostas para as dúvidas colocadas em relação ao futuro e não são as projeções, as especulações ou as expetativas que darão consistência às estratégias e decisões a tomar para o futuro a médio prazo, pois o imediato está resolvido.

Todos querem voltar a ver o Desporto rapidamente em ação e o futebol lidera esta ambição, nos clubes e nos jornais. Praticar futebol, voltar aos treinos significa deixar o isolamento social e voltar ao contacto com os colegas e dirigentes dos clubes. Não é apenas voltar a sentir o cheiro da relva, o que é bom, pois até sugere ausência de infeção pelo coronavírus, mas significa voltar a sentir espaço, frescura na cara e ter rotinas. Estaremos preparados para retornar aos treinos?

Parece ser consensual que apenas estaremos bastante mais seguros com o advento da vacina. Esta, por definição, será eficaz e segura. Dizem que demora mais de um ano e, assim sendo, não é por aqui que os treinos e jogos serão mais seguros no que à transmissão do vírus diz respeito.

A Direção Geral de Saúde tem emitido normas gerais de segurança para a prevenção da transmissão do vírus. A profissão de jogador de futebol tem algumas especificidades que importa considerar, pois causam a concentração de pessoas em espaços relativamente reduzidos (balneário, chuveiros, posto médico, ginásio, local de refeições). O distanciamento social aqui não se aplica, pois mesmo que se iniciem agora treinos com 4 ou 5 jogadores, bem afastados, em horários desfasados, com utilização de 2 ou mais balneários, tal não será solução, pois no futuro todos os jogadores voltarão a juntar-se no mesmo balneário, autocarro ou mesa de refeição.

Deve ser implementado agora aquilo que se adia para mais tarde.

1. O clube deve ser capaz de manter a higienização de todas as instalações, de modo regular e frequente, de cuidar adequadamente da roupa e dos alimentos, de limitar bastante o número de pessoas que fazem parte da equipa, de ter material de proteção (máscaras ou viseiras) para uso, por exemplo, nas deslocações, de ter desinfetantes dispersos pelas instalações, de impedir o contacto próximo com os adeptos, de ser rigoroso na relação com a comunicação social ou outros. Há necessidade de assumir muitas restrições e de limitar a ação de muita gente, o que causará algum desconforto, mas o rigor será compensado.

2. O departamento médico deve realizar a análises aquando do retorno aos treinos e sempre que oportuno, estar atento ao aparecimento de queixas sugestivas da infeção, prever e ter um plano de ação para as várias eventualidades clínicas, ser criterioso na marcação dos tratamentos médicos e nos locais externos de realização de exames, ser exigente na higiene dos equipamentos, incluindo marquesas, e, muito importante, ter poder de decisão.

3. Um quesito muitíssimo importante: a vida privada, a realizada fora do clube, das pessoas que fazem parte da equipa. Todos devem ficar em casa e evitar frequentar locais com muitas pessoas, assim como não devem convidar toda a família ou os amigos para irem lá a casa. As idas a restaurantes cheios, festas, casamentos ou batizados, etc. devem ser evitadas e, quando houver mesmo necessidade de estarem presentes, as precauções universais devem ser implementadas. De nada vale o rigor colocado pelo club nas suas instalações e operacionalização da equipa, se depois, fora do clube, criam-se condições para o contágio pelo vírus. Há necessidade de interiorização mental para a mudança profunda dos hábitos sociais, no sentido do isolamento e da privação de alguns prazeres que a vida voltará a dar lá mais para a frente.

4. A realização dos jogos terá de ser sem público. As bancadas ficarão despidas e tristes, mas seguras. Nelas não haverá transmissão do vírus. Os adeptos poderiam entrar no estádio com máscaras na face, mas teriam eles lavado recentemente as mãos ou as suas roupas estariam sem vírus? No decorrer do jogo, quem controla a colocação das máscaras durante cerca de duas horas, nos momentos de monotonia ou do festejo do golo? Houve-se dizer que Portugal poderá ter 100 mil infetados, o que representa 1\% da população portuguesa. A ser verdade esta percentagem, no estádio com 50 mil adeptos estariam 500 pessoas infetadas, ou seja, existiria uma bomba biológica humana! Certamente que tal não contribuiria para o controlo da atual pandemia ou para a prevenção de uma próxima. O melhor, e para já, é realizar os jogos à porta fechada.

O futebol será diferente, na prática e na assistência ao evento, e as restrições a implementar, por muito rigorosas que sejam, nunca causarão uma situação pior que a atual: estar em casa e sem poder ver futebol ao vivo ou na televisão. Não pode haver outra paragem daqui a 3 a 4 meses. O futebol sairia muito ferido, pois poderiam acabar os patrocínios em geral, mas em muito particular a volumosa contribuição da televisão para os orçamentos dos clubes.

Robert H Mann et al escreveram recentemente no BJSM: "voltar ao desporto será mais do que a retoma dos treinos e de um calendário desportivo renovado". 